\title{
Redes mercantiles e intercambio cultural en la ruta del Galeón de Manila, 1565-1600*
}

\section{Mercantile networks and cultural exchange on the Manila Galleon Route, 1565-1600 \\ Redes Mercantis e Intercâmbio Cultural na Rota do Galeão de Manila, 1565-1600}

Cuaubtémoc Villamar ${ }^{\text {a }}$

DOI: https://doi.org/10.11144/Javeriana.uh89.rmic

Universidad Nacional de Singapur, Singapur

cuau21@gmail.com

ORCID: https://orcid.org/0000-0001-5229-1434

\section{Resumen:}

El artículo presenta un análisis del Galeón de Manila, principal sistema comercial que mantuvo en comunicación a América y Asia, a través del océano Pacífico. Ha sido ampliamente reconocido que este sistema de comercio permitió la apertura del proceso de globalización de la temprana edad moderna. Sin embargo, esta investigación enfatiza en los intercambios culturales activados por el Galeón de Manila, concretamente, en la naturaleza social y cultural de una red de comerciantes instalados en Manila. Se concluye con una reflexión metodológica sobre las herramientas de investigación digital y los enfoques de la historia global y la microhistoria utilizados para comprender el proceso de globalización temprana.

Palabras clave: Galeón de Manila, sistema de comercio, redes comerciales, globalización, intercambio cultural.

\section{Abstract:}

This article presents an analysis of the Manila Galleon, the main trading system that kept America and Asia in communication across the Pacific Ocean. It has been widely recognized that this trade system allowed the opening of the globalization process of the early modern age. However, this research emphasizes the cultural exchanges activated by the Manila Galleon, specifically, the social and cultural nature of a network of merchants settled in Manila. It concludes with a methodological reflection on the digital research tools and the approaches of global history and microhistory used to understand the process of early globalization.

Keywords: Manila galleon, trade system, trade networks, globalization, cultural exchange.

\section{Resumo:}

O artigo apresenta uma análise do Galeão de Manila, o principal sistema comercial que manteve a América e a Ásia em comunicação através do Oceano Pacífico. É amplamente reconhecido que esse sistema comercial permitiu a abertura do processo de globalização do início da era moderna. No entanto, esta pesquisa enfatiza as trocas culturais ativadas pelo Galeão de Manila, especificamente, a natureza social e cultural de uma rede de comerciantes instalada em Manila. Conclui com uma reflexão metodológica sobre ferramentas de pesquisa digital e abordagens para a história global e micro-história usadas para compreender o processo inicial de globalização.

Palavras-chave: Manila Galleon, sistema de comércio, redes de comércio, globalização, intercâmbio cultural.

\section{Introducción}

Una primera parte de este trabajo describe brevemente el sistema del Galeón de Manila. El reto es mostrar el contexto histórico complejo del sistema de comercio con mayor duración en la historia moderna. El marco de la globalización permite analizar el comercio de bienes y el intercambio de ideas, así como la transformación del consumo, a partir de la fundación del Galeón de Manila, en 1571. En esta empresa participaron comerciantes, misioneros, soldados y esclavos de muy diversos orígenes. Esta fase inicial fue determinante porque orientó las tendencias de amplios espacios económicos y culturales, que dieron pie a la primera globalización moderna.

Notas de autor 
La intención es interpretar el fenómeno de la globalización de dio inicio hace cuatrocientos años desde la esfera de la interculturalidad. El comercio transpacífico fue resultado de una intensa interacción cultural, transmitida por la circulación de personas, ideas y objetos, y ha dejado una estela de efectos, aún por estudiar, en múltiples sociedades alrededor del planeta.

A partir de una mirada global, el artículo fija su escala de observación en una red de comerciantes de origen portugués, judíos conversos (cristianos nuevos), instalados en Manila, en el último cuarto del siglo XVI, cristianos nuevos. Esa red tuvo un importante papel en la operación del comercio entre Filipinas y la Nueva España. Lo relevante de ese micro enfoque es que las principales actividades comerciales de esta red mercantil estaban ubicadas en el este y en el sudeste de Asia, con intereses en los virreinatos de la Nueva España y Perú, pero también en Portugal y España. La propuesta central es que esta red comercial muestra características compartidas de tipo cultural, opera globalmente y funciona de manera autorregulada. Lo anterior, no es sorprendente para quienes estudian la complejidad y las redes, pues es precisamente parte de la naturaleza del entramado humano.

El texto cierra con una apreciación sobre el método de investigación empleado para describir redes de comerciantes en el proceso de globalización temprana. Si bien se utilizaron enfoques de la historia global y de la microhistoria, también se emplearon herramientas proporcionadas por la historia digital. Se propone al lector una reflexión que sugiere los pasos para descifrar los múltiples efectos del proceso de apertura de la ruta del Pacífico, disperso hasta ahora en diferentes historiografías, fuentes en varios idiomas y archivos nacionales.

\section{El Galeón de Manila como sistema}

Para analizar los rasgos fundamentales del Galeón de Manila como sistema, se sugiere tener en mente tres circunstancias históricas de largo alcance. Debido a la falta de espacio, estas solamente se esbozan.

1. Se propone rebasar el estudio aislado de las historiografías nacionalistas que plantean una visión fragmentada del conjunto. Acapulco y Manila se identifican en esta investigación como dos nodos de la reglamentación del mecanismo creado en el decenio de 1590 por los participantes en el marco de la monarquía Habsburgo, junto con otros puertos y comunidades localizadas en varios lugares. Principalmente, Sevilla y, en segundo plano, los virreinatos de la Nueva España y Perú.

2. Con el objetivo de medir la naturaleza del sistema de comercio, se propone identificar y examinar la política y andamiaje administrativo de estos imperios. Esto es de particular importancia durante el período de la Unión de Coronas (1581-1640), que coincidió con la transición y consolidación del nuevo sistema de comercio en el océano Pacífico.

3. Desde finales de la Edad Media, la competencia entre las monarquías ibéricas había generado un interés significativo hacia las exploraciones que tuvieron grandes éxitos a finales del siglo XV. Esta competencia tuvo notables resultados expresados en conocimiento geográfico, acerca de navegación y de comercio intercultural. Los principales protagonistas de estos procesos fueron pueblos europeos y, por circunstancias particulares, los portugueses, durante el siglo XVI. Tal riqueza técnico-cultural fue transmitida a la monarquía católica por diferentes vías, incluyendo la acción de los comerciantes portugueses instalados en Asia.

El sistema del Galeón de Manila formó parte de un andamiaje político y económico mayor que abarcaba otros componentes en la región atlántica española y, en una etapa temprana, la experiencia portuguesa en Asia. Las limitaciones de las historiografías nacionales llevaron a que la mayoría de los eventos históricos de la expansión ibérica, ya sea portuguesa o española, se hayan estudiado por separado, y que la Unión de Coronas (1581-1640) haya sido tratada como una anomalía histórica. El largo proceso que llevó a los portugueses a instalarse en Asia se entrelaza con la forma en que los castellanos buscaron por casi medio siglo cruzar el Pacífico desde las Américas y encontrar un camino de retorno. El establecimiento de Manila y el sistema de galeones fue, quizás, la consecuencia más importante de este proceso. Por lo tanto, no debe pasar desapercibida 
la coyuntura de largo plazo que hizo coincidir los intereses de la dinastía Ming y el imperio Habsburgo en el comercio transpacífico, focalizado en Manila.

Se considera necesario dejar atrás la idea de que el Galeón de Manila fue únicamente una línea de tráfico marítimo. En cambio, planteo que fue un sistema de comercio que respondía a los múltiples participantes, tanto a españoles, como a novohispanos e indirectamente a los asiáticos. Teniendo en cuenta la extensión global de los dominios de ambas monarquías en el último cuarto del siglo XVI, las administraciones asumieron responsabilidades considerables sobre grandes territorios. Las crónicas portuguesas y españolas de exploración, escritas por los testigos de aquella época, confirman que hubo múltiples dificultades y frustraciones constantes, derivadas de las deficiencias administrativas y los recursos limitados. La aparente resolución de estas contradicciones fue una compleja descentralización, que sinergizó la agencia de comerciantes, misioneros, administradores profesionales, soldados y varios otros aliados inesperados. La construcción del sistema de galeones de Manila fue un proceso de aprendizaje en el terreno, y no fue necesariamente el resultado de una estrategia emanada de la monarquía. En ese sentido, representa una forma de adaptación constante a la realidad. Un ejemplo de esto es la lista de directrices aprobadas por la corona española para regular el sistema del Galeón de Manila.

Gracias a los nuevos enfoques, es posible observar las contribuciones de múltiples agentes - es decir, los portugueses, vascos, castellanos, andaluces, catalanes, italianos, entre otros - en la expansión de ambas potencias ibéricas. Entre los actores que contribuyeron a la creación de la estructura política global hispánica, se encuentran las comunidades portuguesas, identificadas como de cristianos nuevos. Nuestro análisis se concentra en este punto específico y en cómo se relaciona con las complejidades del dominio global de la monarquía española de los Habsburgo, sobre todo a partir de la unión dinástica del reino portugués en 1581. Las redes de los cristianos nuevos contribuyeron a la configuración del sistema comercial y desplegaron sus conexiones con el apoyo de las monarquías portuguesa y española, las dos entidades políticas prominentes que dominaron la escena europea durante el período moderno temprano.

\section{Nacimiento del sistema del Galeón de Manila}

De manera convencional, se señala que el Galeón de Manila fue un sistema de comercio que operó en el Océano Pacífico durante 250 años (1565-1815) bajo el control y patrocinio del Imperio español. Este mecanismo comercial comunicó de manera continua, regular e institucional dos dependencias de aquel imperio, Filipinas y la Nueva España, aunque los efectos del intercambio llegaron a varias regiones del vasto imperio español. Se insiste en que es un sistema tanto por la formalidad de su reglamentación como por la existencia de las redes comerciales que lo conformaron, es decir, los comerciantes y las mercancías. También rebasó los términos meramente comerciales, pues influyó en el consumo en ambos lados del océano, transportó misioneros, soldados, comerciantes y esclavos, pero sobre todo se convirtió en un nuevo espacio global para el contacto entre culturas diversas y la transmisión de ideas ${ }^{1}$.

Existe una amplia literatura acerca del Galeón de Manila, pero el libro de William Lyte Schurz. (1939) The Manila Galleon, New York: Dutton \& Company, continúa siendo el más completo en la materia. Los lectores también pueden consultar el libro en línea de Oscar H.K. Spate. (2004) The Spanish Lake. Canberra: The Australian National University. Un texto contemporáneo en español que abarca el largo plazo del comercio es Carmen Yuste. (2007) Emporios transpacificos: comerciantes mexicanos en Manila, 1710-1815. México: UNAM. Salvador Bernabeu Albert (ed.) (2013) La Nao de China, 1565-1815. Navegación, Comercio e Intercambios Culturales. Sevilla: Universidad de Sevilla. Carmen Yuste (ed.) (2019)

No se rechaza el enfoque macroeconómico que ha aportado un cambio relevante en la interpretación del papel de la plata en el sistema mundializado, teniendo como puntos nodales Manila, México y Perú. Las aportaciones de Dennys O. Flynn y Arturo Giráldez tienen la virtud de correlacionar procesos en Asia, 
América y Europa mediante la explicación de la monetización de la economía china y la ingente producción de plata en los virreinatos de Nueva España y Perú, bajo la sombra del imperio Habsburgo (O’Flynn y Giráldez 1995 y 2002). Sin embargo, el enfoque utilizado aquí va al cableado humano del sistema, asociado a las redes comerciales.

En sus primeras décadas de existencia, el comercio a través del Pacífico inició sin reglas ni límites de carga, más allá del espacio de las naves de 200 toneladas que hacían el dilatado viaje entre Manila y Acapulco, a más de 14000 kilómetros de distancia ${ }^{2}$ (Hidalgo, 1995). Fue hasta 1593 que se estableció una reglamentación precisa, llamada Permissión, que instituyó la distribución de la carga por medio de boletas, asignadas a los habitantes españoles de Manila. Se limitó la carga a 300 toneladas, y en décadas posteriores el éxito del comercio condujo a un aumento de la capacidad de las naves hasta 500 y 600 toneladas. En el siglo XVII, se llegaron a tener galeones de hasta 1000 toneladas, como Nuestra Señora de la Covadonga, asaltada por el corsario inglés George Anson, en 1743.

Se estableció un límite de 250000 pesos al valor total de las mercancías en el galeón que salía de Acapulco a Manila y de 500000 pesos al que regresaba de Asia a América. Esos montos aumentaron con los años y llegaron a fines del siglo XVIII a 750000 de ida y un millón y medio al regreso. El comercio del Pacífico debía pagar los siguientes impuestos: almojarifazgo, sobre el valor de la carga pagadero en México; avería, para la defensa de la navegación; almirantazgo, para pagar los servicios portuarios y alcabala, que era el impuesto a la venta en el tránsito de Acapulco a la Ciudad de México (Yuste 2007, Giráldez 2015).

Cabe destacar que esta primera fase del sistema de comercio a través del Pacífico se enmarcó en el período de Unión de las Coronas, bajo el dominio de Castilla sobre Portugal, a partir de 1581 y hasta 1640. A pesar de la separación formal de los espacios portugueses y españoles de ultramar, redes de comerciantes portugueses ocuparon un lugar importante en el intercambio tanto en el Atlántico como en el Pacífico (Boyajian, 1983, 1993, Studnicki-Gizbert, 2007). Un proceso similar se desarrolló en el lado americano del Pacífico. La corona prohibió en fases sucesivas el comercio directo entre Filipinas y Perú, y entre México y Perú, debido al temor de que la plata sudamericana se desviara hacia el oriente. Sin embargo, el comercio entre los dos virreinatos se mantuvo de manera intermitente, solapada por las autoridades o triangulada en puertos de Centroamérica, ya entrado el siglo XVII (Suárez 2015).

En esta etapa inicial, en la Nueva España se instauraron ferias ocasionales de comercio en Acapulco, aunque las mercancías se distribuían en Ciudad de México, en donde se comerciaba parte de la carga que no venía comisionada. Así, se consolidó el papel de la Nueva España como nodo descentralizado del imperio para el comercio, la recaudación fiscal, la defensa y la difusión misionera proyectadas para el Pacífico. Esta forma ad-hoc de descentralización se convirtió en objeto de estudio, identificado como un sistema policéntrico del imperio español (Cardim, Herzog, Ruíz 2014).

Normativas posteriores, decretadas en el siglo XVII, afinaron el sistema para evitar el acaparamiento de la carga, la evasión de impuestos, el exceso de peso que ponía en peligro el viaje de los galeones y la estricta prohibición de que los viajes se desviaran de la ruta establecida. El tema de la corrupción era considerado como un atentado en contra de Dios y la Corona, por lo que era perseguido de manera formal, aunque seguía los actos prohibidos siguieron ocurriendo; por ejemplo, el ocultamiento de mercancías valiosas, el cohecho a los encargados de las aduanas y el transporte de cantidades mayores de plata de las declaradas, en el viaje de Acapulco a Manila. El contrabando hacia los puertos de Sudamérica continuó en lugares como Huatulco, en la costa mexicana del Pacífico, donde arribaban comerciantes del Perú. A pesar de las medidas de control, comerciantes sudamericanos continuaron viajando a la Nueva España y cruzaron hasta Filipinas (Borah 1975, Yuste 2007, Iwasaki 2011, Bonialian 2012).

Otro paso hacia la organización del comercio fue la fundación en 1594 del Consulado de México, que congregó a los principales mercaderes con intereses en el comercio en el Pacífico y el Atlántico. Esta institución político-comercial de la comunidad mercantil fue un foro para dirimir el conflicto de intereses comerciales entre Europa, la Nueva España y Filipinas (del Valle 2005). En siglos posteriores se observó un equilibrio 
inestable entre esos intereses, como reflejo de las fluctuaciones del comercio, la concentración de poder y la percepción de que los mexicanos o los filipinos, en su mayoría, representantes de intereses de la Nueva España, dominaban el comercio del Pacífico.

Es importante aclarar que, en el marco de un régimen de comercio dirigido bajo el esquema mercantilista, la intención de la Corona española era aumentar la regulación, para reducir costos y contrabando. A partir de la década de 1590, se puede calificar al Galeón de Manila como un sistema de comercio que respondía a los múltiples actores participantes: españoles, novohispanos, e indirectamente, asiáticos. Otra característica del sistema era la regularidad de los galeones que atravesaban el océano Pacífico, los impuestos que se debían pagar y el volumen de carga autorizada. El sistema era regular, confiable para los participantes, y la Corona asumía los costos del transporte y la defensa del trayecto, los puertos y los navíos, ante el acoso de piratas.

Al iniciar el siglo XVII, el sistema de comercio en el Pacífico atendía a tres principios ampliamente debatidos y aprobados por las partes interesadas: legalidad de las transacciones, previsibilidad del transporte y seguridad del comercio. Para los grupos de comerciantes profesionales, quedaban dos responsabilidades en sus manos: reunir recursos financieros y cubrir el riesgo en caso de pérdida de la carga ${ }^{3}$ (Iaccarino 2011). Un primer esfuerzo sistemático de análisis del comercio fue introducido por Pierre Chaunu en la segunda mitad del siglo pasado, con el estudio de los archivos de aduanas de Sevilla (Chaunu 1974). Aunque el trabajo ha tenido seguidores, es tan vasto que no se ha logrado una revisión completa del monumental acervo estadístico sobre cientos de viajes realizados en ambos sentidos, durante la larga vida del sistema. En el marco de la historia cuantitativa, la investigación de Chaunu detalló las regulaciones oficiales sobre la administración del transporte marítimo, los puertos, los impuestos y la autorización de los viajeros en la ruta de Acapulco a Manila. Su libro sobre el comercio entre Manila y Acapulco cambió muchas percepciones del Galeón de Manila, dominadas, hasta entonces, por la historia de las misiones católicas y la historia política, pero distanciadas de análisis importantes acerca de la relación económica y la interacción cultural circular con Asia. En la actualidad, es posible extraer gran cantidad de información y elaborar bases de datos más o menos homogéneas, mediante la integración de cambios de clasificación de las mercancías que se dieron durante la historia del galeón y faltantes de varios años. Este constituye un campo fértil de exploración de análisis de grandes datos (big data).

Un giro historiográfico que se dio al final del siglo XX fue el estudio del flujo de plata americana para el pago de la administración española en Filipinas y, crecientemente, la adquisición de mercancías asiáticas. Este enfoque, que podría ubicarse en la historia económica, propició un nuevo entendimiento de las implicaciones globales del comercio en el Pacífico (O’Flynn y Giráldez 1995). El comercio de bienes suntuarios que han glorificado los estudiosos del arte fue relativamente pequeño, en un principio, pero se incrementó con el tiempo en proporción al espacio de carga y la capacidad de adquisición de las élites americanas y europeas. Este tipo de intercambio tuvo su auge hasta finales el siglo XVII (Curiel 2016).

Los trabajos de Flynn y Giraldez afirman que el inicio del sistema comercial del Pacífico en Manila, en 1571, representa el nacimiento de la globalización. Los autores se centran en el efecto a largo plazo de la interrelación del comercio entre Manila y Acapulco; específicamente, en que el flujo de plata americana, descubierta en abundancia en Potosí (hoy Bolivia), en 1545, y en Zacatecas en México, en 1546. La abundancia de plata en América coincidía con la ingente demanda de ese metal en la economía china, en el ocaso de la dinastía Ming. Estos procesos, tanto en América como en Asia, maduraron lentamente a lo largo del siglo XVI, hasta que entraron en contacto debido al descubrimiento técnico de una ruta marítima relativamente estable, bajo control político y militar del imperio Habsburgo. 


\section{La construcción de una red de comercio}

La información obtenida en los archivos permitió identificar los datos de 83 comerciantes que operaban tanto en el espacio asiático portugués de India al sudeste de Asia, Macao y Japón, como en el comercio del Galeón de Manila, desde la capital de Filipinas hasta Acapulco, con contactos en centros mineros de plata del siglo XVI en la Nueva España. Las ramificaciones llegan hasta el comercio de esclavos africanos en Cartagena de Indias y el comercio de mercancías asiáticas en Perú. De hecho, los comerciantes siempre mantuvieron contacto con Lisboa y Sevilla, entre los principales puertos del espacio ibérico.

El caso más notable es el de Diego Hernández Victoria o Diogo Fernandes Vitoria, quien residía en Manila desde la década de 1580 y había construido una red de relaciones que cruzaban la pretendida división entre los espacios portugués y español, en Asia (AGN, México, Inquisición, vol. 162). Llegó a ser miembro del Cabildo de Manila y fue administrador de la construcción de la fortificación de la nueva ciudad, Intramuros, una muralla que hoy distingue a Manila. En esa calidad de ciudadano prominente estuvo a favor del comercio entre Manila y Macao y de las propuestas de los comerciantes de Manila para establecer la regulación de 1593. Otro portugués residente en Manila fue Pedro de Brito, quien siguió una carrera política unida a la de Hernández Victoria, miembro del Cabildo de la ciudad, aunque no fue acusado por la Inquisición. A partir de 1581, Felipe II se adhirió a la Corona portuguesa, pero con la promesa ante las Cortes de Tomar de mantener separadas las administraciones en los territorios de ultramar. Para ese entonces, los mercaderes portugueses mantenían amplias redes comerciales en los mercados asiáticos que resultaron de utilidad para los castellanos recién llegados a la región.

Desde el puerto de Macao, estos comerciantes se desplazaban por toda la región y lograron en pocos años incidir en el comercio del Galeón de Manila (Miyata 2017). Otro personaje que destaca en la vinculación entre Macao y Manila en la década de los ochenta fue Bartolomeu Vaz Landeiro, mejor conocido como Bartolomé Báez Landero (Boxer 1948). Era esencial la alianza de este grupo de comerciantes con capitanes, pilotos y militares, como Esteban Rodríguez de Figueroa y Juan Xuárez Gallinato, ambos con prestigio propio en las últimas décadas del siglo XVI.

Específicamente, las ventajas acumuladas por los comerciantes portugueses en el lado asiático del comercio del Galeón de Manila eran: el conocimiento sobre navegación, cartografía regional y los diversos tipos de embarcaciones necesarias para moverse en la región, sobre todo bajo los ritmos del monzón. Una ventaja notable de estos comerciantes era el conocimiento de los idiomas o el uso de traductores a una variedad de lenguas de comercio como el chino, el japonés y el malayo (Barreto 2016). También contaban con el manejo de sistemas de contabilidad avanzada que adquirieron de los comerciantes genoveses y venecianos. Les distinguía el conocimiento de los sistemas de financiamiento del comercio de largas distancias y el pago de riesgo por medio de asociaciones colectivas, como la Cofradía de la Misericordia. Fueron activos en las tareas comunitarias para fortalecer la seguridad y la administración de los puertos, este fue el caso de la construcción de la muralla de la ciudad de Manila y de navíos para la carrera del Pacífico y entre puertos del sudeste de Asia.

Un descubrimiento muy relevante fue el vínculo que Diego Hernández Victoria mantuvo con la administración de la catedral de Ciudad de México. Se toma en consideración que en la Nueva España ese núcleo, mezcla de religioso y seglar, llevaban la contabilidad de la iglesia más importante de la colonia. Era una época en que el financiamiento al comercio estaba controlado por la Iglesia católica por la vía del crédito y tenía vínculos con el desarrollo de la minería de plata y el comercio externo. La estrecha relación entre Hernández Victoria, en Manila, y el sacerdote Francisco de Paz, en México, muestra este tipo de contactos. El segundo recibía las mercancías asiáticas enviadas desde Manila y fungió como albacea de los bienes de Hernández Victoria, en Tacubaya, México (AGN, México, Inquisición, Vol. 251, exp.1).

El expediente de otro personaje acusado por la Inquisición, Antonio Díaz de Cáceres, muestra la manera en que la red mantenía la relación con prominentes portugueses en América y en Asia (AGN, Méxio, Inquisición, Vol. 159, exp.1). Estos, por un lado, estaban ligados al comercio de plata y la circulación de mercancías de 
Asia, y, por otro, llevaban a cabo el tráfico de esclavos, vía Cartagena de Indias, hacia la Nueva España. Díaz de Cáceres estaba relacionado con la familia del gobernador Luis de Carvajal, cuya hermana y sobrinos fueron procesados por la Inquisición. El caso de esta familia es considerado el más notable de la época en la Nueva España, aunque los autores que han publicado sobre este tema minimizan los vínculos con Asia.

En cuanto al tema aquí estudiado, un golpe mortal a la red de comercio fueron los procesos de la Inquisición contra algunos de los principales miembros, como Diego Hernández Victoria y los hermanos Domingo y Jorge Rodríguez, así como la muerte de una generación entera de la que se perdió el rastro a principios del siglo XVII. La investigación sobre la Inquisición contra Hernández Victoria inició en 1597 y continuó a pesar de su muerte en ese año. Concluyó una década después, cuando se reconoció que no se encontraron pruebas de que el mercader fuera apóstata o hubiera renegado de la Iglesia católica.

Así, se encuentran nuevamente redes de comerciantes portugueses activos en el comercio del Pacífico, durante las tres primeras décadas del siglo XVII (Uchmany 1992). Sería equivocado ver a las redes comerciales como algo estático, por lo tanto, el enfoque metodológico más adecuado es observar los cambios en el tiempo (Bötche, Hausberger, Ibarra 2011). Simón Váez Sevilla fue un rico comerciante de la Nueva España, con lazos comerciales con Europa, Perú y Filipinas. En Lima, su socio Juan Bautista Pérez fue inmolado en 1639 en la hoguera de la Inquisición y, en 1649, Váez Sevilla fue condenado al exilio (Uchmany 1998). Es posible considerar que la intención de eliminar toda raíz relacionada con los portugueses, en el comercio del Pacífico y en la economía de la Nueva España, obedeció a la separación de Portugal de la Unión de las Coronas en el año 1640. El propio virrey Escalona fue defenestrado por el obispo Juan de Palafox, en 1642 por la desconfianza de la Corona respecto a su lealtad. Su primo, el duque de Braganza, se había coronado ese año como Juan IV de Portugal (Villamar 2015).

\section{Globalización del comercio, las ideas y el consumo}

Para los propósitos del artículo, es muy importante el estudio de las mercancías como vehículos culturales, subrayo siempre el contexto histórico-cultural de las sociedades que las producían y las que las consumían. El contenido simbólico de una pieza de marfil, por ejemplo, tallada en un puerto colonial portugués, o por artistas chinos en Manila, adquiría un significado religioso, ornamental y de prestigio social mayor en Zacatecas, México o Lima, generalmente, por encima del monetario. Es fundamental proseguir la interpretación de este tránsito cultural a través del Pacífico para recabar los cambios sociales de largo plazo, en las percepciones em ambos lados del océano más grande del mundo. Para esto, es necesario revisar el origen del comercio que dio vida al Galeón de Manila y, como he planteado en otra oportunidad, tuvo su dinámica principal en la variedad cultural de Asia y la abundancia de mercancías, acompasada por la transformación del consumo, sobre todo en las colonias españolas de América ${ }^{4}$ (Villamar 2016).

Un elemento que es necesario destacar es la presencia prominente de las mercancías asiáticas en América, influida por la ostentación. Este es un caso compatible con el concepto desarrollado por Arjun Appadurai acerca de la vida social de las mercancías. Aunque la búsqueda del beneficio jugó un papel en el proceso, muchos otros elementos no económicos permitieron la circulación de esas mercancías. El comercio representaba más que el precio relativo de la mercancía porque los productos eran los vehículos para el intercambio de valores y eran aceptados como interfases políticos y culturales. Vale la pena observar que los relatos escritos en esa época privilegiaban la información sobre productos de alta calidad, piedras preciosas, especias y aromáticos, entre otros (Appadurai 1988).

Una narrativa histórica eficaz de este período inicial permite describir la complejidad del proceso globalizador inducido por el Galeón de Manila. Para esto, se requiere resaltar la condición social del comercio intercultural, es decir, no limitarlo al aspecto material ${ }^{5}$ (Curtin 1984). Dos rasgos específicos de este enfoque son: primero, toda la actividad económica está sujeta a una atmósfera cultural y no, como se ha insistido en 
el siglo XX, que la economía es la esencia de toda acción humana ${ }^{6}$ (Polanyi 2001). Segundo, todo comercio que rebasa el ámbito de una sociedad cerrada, por el hecho de trascender fronteras sociales, comienza a ser comercio intercultural $^{7}$ (Curtin 1984). Estas premisas permiten afinar el contexto histórico particular en el que se desarrolla el intercambio.

Solamente una visión ahistórica desconoce las múltiples formas de intercambio que existían antes de la globalización del siglo XVI, como el trueque, el intercambio ritual o el tributario, entre otras transacciones que casi nunca empleaban dinero metálico y que perduraron bien entrado el siglo XVIII (Bin 2019). Los comerciantes peregrinos llevaban consigo concepciones del mundo, entre los cuales se encontraban conceptos biomédicos que compartían con otras culturas. Una coincidencia de todos los participantes en estos intercambios era que "buscaban las mismas sustancias animales, especias y gemas para potenciar el sexo, la reproducción y la salud física”. A este tipo de productos, como el almizcle y las piedras bezoares, se les denomina productos carismáticos, "junto con los símbolos reales, como los metales preciosos, el armamento y los caballos, la búsqueda de medicinas valiosas impuso tendencias profundas a los desplazamientos y al comercio de los pueblos" (Bayly 2004).

Los intentos de adaptar modelos económicos del siglo XIX para comprender el sistema del Galeón de Manila, que nació en una etapa inicial del mercantilismo, se han encontrado con información escasa y no ha podido definir una "racionalidad" aparente de los agentes económicos. Para contrastar estos enfoques de mercado, es necesario estudiar los diversos ámbitos culturales existentes en los puntos geográficos en que se desenvolvía el comercio (Sánchez y Kaps 2017). Se requiere un enfoque interdisciplinario, que contemple tanto las descripciones escritas de la época - que por supuesto cargan con su propio contenido ideológicoreligioso- como por la cultura material que aún perdura y que expresa muchos de los principios sociales y culturales de sociedades del pasado. Se trata de hacer una arqueología de la experiencia cultural y económica del pasado.

Sin embargo, Flynn y Giráldez y otros autores han hecho un esfuerzo para considerar que el Galeón de Manila fue un hecho cultural que se insertó en la formación histórica de múltiples sociedades y que ha sido heredada hasta la actualidad (O’Flynn y Giráldez 1988, Giráldez 2005). La breve revisión de ese proceso histórico permite comprender la forma en que un sistema comercial como el Galeón de Manila estuvo anclado en un ámbito cultural y, para los propósitos de este artículo, subraya el hecho de que las redes de comerciantes fueron el cableado cultural que sustentó dicho sistema.

Es posible observar este sistema desde un ángulo diverso: el estudio de los puertos del sudeste Asia, fuente idealizada de riquezas y especias. Un enfoque de este tipo proporciona claridad sobre las vinculaciones centenarias que existían en la región antes de la llegada de los europeos; relaciones de intercambio que estaban en manos de comerciantes de diferentes orígenes y religiones. Los centros de poder político en el sudeste de Asia eran relativamente inestables, con cambios de capitales, alianzas subregionales, dinastías y lealtades en constante mutación. Se vivía un proceso de centralización política, consolidación de las élites y los Estados. La inestabilidad y la dinámica del sudeste de Asia estaban marcadas también por la influencia de los grandes centros de poder de India y de China. En el curso del siglo XVI, los portugueses fueron los primeros europeos en integrarse en tales procesos. Estos se adaptaron a la fluidez de las sociedades locales y a sus formas de intercambio. La ocupación española en Filipinas, al finalizar esa centuria, se realizó con un método más agresivo y en la coyuntura particular ya mencionada de los cambios en China y Japón (Lieberman 2003, Subrahmanyam 2012).

Estas formas de pensamiento gobernaban la actividad comercial, en general. Los puertos de Asia del este y del sudeste recibían en ese período a multitud de comerciantes de diversas creencias. Los puertos marítimos en la macrorregión deben ser estudiados como nodos que transmitían las experiencias comerciales de orígenes diferentes. Esos puertos admitían la actividad considerada legítima, en oposición, a la piratería en el mar. La hospitalidad para los viajeros, el nombramiento de autoridades de orígenes diversos para administrar el comercio, la solución de controversias por parte de jueces locales, era garantía de continuidad del comercio. 
Las costas del actual territorio de Malasia, Singapur e Indonesia contaban con puertos de diversos niveles y productos, a los que arribaban comerciantes desde el mundo árabe, la India y China, entre otros. El islam comenzó a difundirse rápidamente en aquella época. Desde siglos atrás, indios y chinos comenzaron a asentarse, primero por temporadas, en los puertos del sudeste de Asia, y se convirtieron con el paso de los años en pobladores locales particulares, que mantenían sus idiomas, costumbres y contactos con las costas del sur de China. Filipinas era parte de esa constelación de puertos, particularmente, en las islas del sur, Mindanao y Cebú, bajo influencia musulmana.

Quienes estudian la historia colonial de América podrán comprender que esta descripción abarca un espacio geográfico extremadamente amplio. Se coloca en un mismo plano lo que ocurría en los virreinatos de la Nueva España y Perú, es decir, se trata de una perspectiva muy general que se arriesga a perder de vista muchos matices. Sin embargo, la historia global sugiere, precisamente, abrir el obturador de la cámara, para captar nuevos ángulos y detectar partes del conjunto que no se tenían en cuenta cuando se estudiaba el pasado con microscopio. Es creciente el número de estudios que aceptan — fuera del ultranacionalismo castellano que amenaza con volver a dominar la difusión histórica-, que el avance ibérico en Asia fue producto de múltiples esfuerzos, es decir, que incluía los avances portugueses, castellanos, vizcaínos, andaluces y novohispanos, entre $\operatorname{otros}^{8}$ (O’Gorman 1995, Echeverría 2014). La adaptación a las condiciones de los mercados del sudeste de Asia, por parte de los mercaderes portugueses, por ejemplo, fue una ventaja fundamental que fue transmitida a los comerciantes castellanos y permitió el éxito de Manila como "nuevo puerto" asiático.

Más allá del enorme impulso expansivo de los ibéricos, estaba el resto del mundo que mantuvo sus organizaciones políticas y sus expresiones culturales, hasta la llegada del alto imperialismo. Insisto en el caso de la política económica de la dinastía Ming, con un efecto inesperado sobre el proceso de globalización planetaria descrito. Los estudios académicos especializados destacan, por ejemplo, la coincidencia del establecimiento de la reforma fiscal ( Yi Tiao Bian Fa) en la segunda mitad del siglo XVI, que, al decretar el pago de impuestos sobre la plata, estimuló la demanda china del metal. La plata provenía principalmente de Japón, que vivía un proceso interno convulso rumbo a la unificación del shogunato. Paralelamente, la apertura del comercio exterior desde la década de 1570 en las regiones costeras del sur de China "coincidió" con la apertura de la ruta transpacífica, lo que abrió la puerta al caudal de plata mexicana y peruana e incrementó la demanda de productos asiáticos. Estas dos decisiones internas de China fueron fundamentales para el ingreso masivo de plata americana - un choque externo, en lenguaje económico- en el medio fiscal y comercial de China (O’Flynn y Giráldez 1995). En aquel momento histórico, al otro lado del Pacífico, Perú y México experimentaban los inicios de la producción de plata, estimulada por las necesidades de pago del imperio Habsburgo. Las sociedades americanas, bajo el dominio español, vivían una transformación acelerada de sus economías y sus culturas, con la explotación de la minería y de grandes espacios agrícolas con mano de obra indígena semiesclava. Se fundaron decenas de ciudades de tipo europeo, bajo la norma estricta de la religión católica romana y el idioma español. Las sociedades de la América colonial se convirtieron en las principales exportadoras del medio de pago aceptado por el mundo (Bakewekk 1984). En la medida en que la economía china funcionó como una virtual aspiradora de plata a nivel global, se reorganizaron las prioridades en los lugares de producción del metal (O’Flynn y Giráldez 2002, Atwell 2008). El comercio, un oficio que no era bien visto por la clase propietaria europea, se convirtió a principios del siglo XVII en una de las formas más dinámicas de acumulación y expansión en los nuevos espacios americanos. Las consecuencias de esta rápida interacción entre sociedades tan alejadas se expresaron a través de mecanismos de adaptación económica, social y cultural, o incluso, de rituales de resistencia generados por las culturas locales, como lo propone el Principio Potosi (Suárez, Sancho, Vásquez 2012).

La primera expansión europea de la temprana edad moderna, encabezada políticamente por el imperio Habsburgo, tuvo como expresión cultural el barroco y la dinámica de la Iglesia católica romana, en lucha contra el cisma protestante y en busca de la entronización a nivel planetario. Esta dinámica de dominio se impuso en el ámbito atlántico desde el descubrimiento de América y continuó con una expansión que 
consideraba al islam como obstáculo contra el que era necesario combatir para dominar todo aquello que fuera diverso o ajeno a la religión católica romana. En el escenario europeo del siglo XVI, la división entre protestantes y católicos, que se venía gestando siglos atrás, hizo que la expansión misionera adquiriera atributos militantes y militares. La compañía de Jesús es una muestra del instinto hegemónico europeo que mantuvo un proyecto misionero novedoso en China y Japón, bajo un modelo cultural complejo: el barroco.

A partir de la definición elaborada por Werner Weisbach, que coloca el arte barroco como un instrumento de la política de la Iglesia católica para contrarrestar el desafío de la cultura protestante en Europa, es ampliamente aceptado el sólido vínculo que existió entre la Contrarreforma y las expresiones barrocas del siglo XVII y hasta mediados del XVIII (Weisbach 1984). La Iglesia católica romana militante estaba siempre alerta contra la posible influencia de los protestantes ingleses y holandeses, y veían en otras expresiones no católicas enemigos potenciales, como los musulmanes del sudeste de Asia. Igualmente, los misioneros católicos fueron expertos en el arte de la diplomacia en las cortes asiáticas. Los regalos de gran valor, en especial en China, tenían un grado de sofisticación y detalle que demuestra la experiencia y el rápido aprendizaje de los rituales cortesanos y los idiomas para evitar cometer errores. Varios de los presentes llevados por los jesuitas a la corte china (relojes, clavicémbalos, mapas, etc.) se conservan en el Palacio de la Ciudad Prohibida, donde fueron muy bien recibidos por los emperadores de las cortes Ming y Qing (Kai 1977). La división entre misioneros portugueses y españoles no desmerece el hecho de que todas las órdenes religiosas siguieron el modelo barroco en sus acciones, como de hecho también sucedió en las regiones bajo control protestante.

El encuentro cultural que involucró a Europa con América y Asia se encuentra representado en aquellos los variados rasgos barrocos. Algunas expresiones propias de la época eran: el temor a la muerte, por ejemplo, en el mar; las aportaciones al lenguaje como resultado de la aparición de nuevos objetos y sujetos; la difusión de la música como interpretación y traducción entre culturas lejanas (Irving 2010). El barroco constituyó el marco cultural del encuentro en aquella primera globalización que llegó a Asia. Ciudades como Macao y Manila fueron diseñadas conforme a los cánones europeos (Reed 1978, Tambling 2009). Se desplegaron toda suerte de herramientas culturales para ampliar la mirada del mundo, con el propósito de abarcar todo el planeta.

Serge Gruzinsky, entre otros, ha mostrado el eslabonamiento que sucedió a nivel planetario, a partir del encuentro de cultural en el Pacífico (Gruzinski 2014). La globalización de esa época cerró la circunferencia del planeta por el lado del Pacífico, al acelerar el intercambio biológico, representado por nuevos cultivos, gérmenes y medicinas desde ambas orillas del océano. Por esa razón, es oportuno integrar la información acumulada por diversos estudios sobre este intercambio natural, dado que modificó los usos y costumbres de los pueblos de la cuenca del Pacífico. Este es el caso del maíz, la patata, el camote, el chile, de origen americano en toda Asia, así como la llegada de productos como el tamarindo, el mango, la palma de coco y el arroz de tipo asiático a suelo mexicano o peruano. Lo que interesa establecer en este punto, más allá del hecho biológico que es tan importante, es el cambio cultural que se produjo en los diversos estratos sociales de la mayoría de la población, desde el encuentro entre Asia y América (Machuca 2014). Actualmente, el chile y el maíz son parte fundamental de la alimentación en amplias áreas desde las alturas de la meseta tibetana hasta el sudeste de Asia continental. La integración de asiáticos que viajaron gracias al Galeón de Manila, muchos de ellos en calidad de esclavos o viajeros forzados, fue un ingrediente importante entre los pueblos indígenas de la costa del Pacífico en México y Centroamérica. Existen registros de la presencia de la cultura asiática muy temprano en el virreinato peruano, o al menos en su capital, Lima (Oropeza 2011, Seijas 2008, Bonialian 2015).

El contenido barroco de la cultura en formación en la Nueva España y Perú se amalgamó con las culturas prehispánicas, lo que indujo varias formas de mestizaje étnico y adaptación social. El ingrediente asiático llegó por la vía del Galeón de Manila, tanto a las capas con mayor poder de compra de las sociedades, como a los niveles populares urbanos, en los cuales permeó el uso y la copia de modas asiáticas. Un papel que comienza a ser estudiado fue la influencia de los migrantes forzados, marineros filipinos y esclavos asiáticos, en las comunidades indígenas del occidente mexicano. Una observación interesante es que los productos artísticos asiáticos circularon en el espacio imperial de Habsburgo, primero en forma de regalos, piezas religiosas 
destinadas a cofradías e iglesias, que no aparecen como mercancías para ser comercializadas entre el amplio público (Gasch-Thomas 2014).

\section{Las redes comerciales en el océano Pacífico}

La historia global procura integrar la multitud de elementos que estuvieron involucrados en la creación de redes humanas que abarcaron enormes distancias. Es tiempo de dar espacio al fenómeno cultural, como un proceso envolvente de comunicación y significados, que cohesionó a las comunidades y que puso en contacto a grupos sociales diferenciados, geográfica y temporalmente. La cultura barroca europea y su vinculación con América fue determinante para la consolidación de instituciones políticas, prácticas sociales y expresiones artísticas durante el proceso inicial de globalización. Esta concepción del mundo se reflejó en la percepción que se tuvo de los pueblos asiáticos, vistos con fascinación por los misioneros, comerciantes, funcionarios y viajeros, entre los siglos XVI y XVIII. La narrativa constante de aquellas épocas transitaba de la admiración ante el orden social de los pueblos asiáticos hasta el rechazo por no ser católicos romanos.

En la base de este nuevo ambiente complejo se encuentran las redes de comerciantes que se comunican alrededor del mundo, a distancias apenas conocidas por algunos individuos. El intercambio de información de estas redes sobre disponibilidad de productos, precios, créditos y seguros es indicativo del nivel global alcanzado en ese proceso. Los mercaderes mantenían actualizada su contabilidad y confiaban en la práctica notarial europea para hacer tratos con comerciantes europeos y locales. La escala del fenómeno comercial se dimensiona también en el hecho de que, verdaderamente, abarcaba al planeta conocido por los europeos. Un fenómeno conduce al siguiente. Inicialmente, los europeos en Asia buscaban especias, que eran los productos disponibles únicamente en un grupo de islas en el remoto sudeste de Asia. Pronto, se encontraron con una oferta casi ilimitada de otros productos naturales y manufacturas asiáticas. La oferta modificó la demanda de tales productos, tanto en América como en Europa.

En años recientes, el marco de análisis de las redes comerciales ha tenido nuevos desarrollos, principalmente, con el uso de las tecnologías de información aplicadas a las humanidades. Algunos análisis relacionales y el estudio de las redes como parte de la complejidad aportan nuevas interpretaciones a la dinámica de los actores dispersos en el comercio mundial, entre los siglos XVI y XVII., Diversos autores principalmente europeos forman parte de esta corriente en Europa y Estados Unidos que estudia redes comerciales como parte de sistemas complejos durante los primeros años de la modernidad (Ramada y Molho 2002, Owens 2011, Trivellato 2011 y 2014, Hausberger e Ibarra 2014, Ribeiro 2015, Herrero y Kaps 2017).

Un antecedente de este tipo de interpretación, aun cuando no se hablaba explícitamente de redes, son los trabajos de James Boyajian y Daviken Studnicki. Estos estudios muestran la evidencia del papel desempeñado por las comunidades de banqueros y comerciantes en el nuevo comercio global bajo la autoridad del dominio de los Habsburgo (Boyajian 1983 y 1993, Studnicki 2007). Ambos autores aportan separadamente amplia información y sus enfoques son complementarios acerca de la diáspora comercial en el reino del Imperio español, cuando Portugal estaba bajo el dominio de los Habsburgo (1580-1640). Ambos autores proporcionan información abundante y detallada sobre la composición de las redes comerciales, principalmente de la filiación neocristiana, en todo el mundo. Desde el punto de vista político, Boyajian explica la compleja relación de la Corona real española con la comunidad judía. Estas redes desempeñaron un papel importante en la financiación de la administración imperial e influyeron activamente en las rutas comerciales en el Atlántico, el Pacífico y la India. No obstante, las élites de conversos, aunque ocupaban lugares prominentes en los negocios, siempre estuvieron bajo sospecha de ocultar su verdadera filiación religiosa. De hecho, algunas estuvieron expuestas al constante acoso por parte de las Inquisiciones española y portuguesa.

La contribución más relevante de Boyajian es la integración de decenas de casos de banqueros y ricos comerciantes de origen judío, activos en Europa, pero con operaciones en todo el mundo a principios 
del siglo XVII. El trabajo de Studnicki también es importante porque se centra con mayor detalle en las prácticas mercantiles de los comerciantes, relacionadas con los rasgos culturales de las comunidades judías. Aunque algunos de los principales actores se consideraron cristianos o habían abandonado su religión pocas generaciones atrás, continuaron utilizando redes privadas dentro de sus comunidades para la transmisión de información (comercial, financiera, política) en África, Asia y América. La denominación que otorga Studnicki a esas redes corresponde a su identidad de cristianos nuevos y, como ellos se conocían, es decir, como Nación.

"The Nation lacked a unified and institutionalized form of political authority. Instead, the expatriate communities and merchand who constituted the Nation were federated by superimposed links of commercial association, kinship, provenance, and sociability." (Studnicki, 2007, p. 19).

Para un análisis más detallado del concepto de nacionalidad ver la aportación de Tamar Herzog (Herzog 2011).

Otros estudios específicos, que enriquecen la interpretación y aportan valiosa información sobre el origen y la operación de estas redes portuguesas en el espacio asiático, están representados por los trabajos de Amélia Polónia, Armadio Barros Rila Mukherjee (Polónia, Barros y Nogueria 2011, Mukherjee 2011 y 2013). En la Universidad Nova de Lisboa se desarrolla un ambicioso proyecto colectivo encabezado por Elsa Penalva, que estudia el despliegue de comerciantes portugueses en Asia, mediante el método de la prosopografía, es decir, la identificación de los individuos que forman tales comunidades (Penalva 2008).

La información acerca de múltiples casos de mercaderes de origen portugués quedó asentada en los informes de la Inquisición. El propósito de varios interrogatorios del Santo Oficio en contra de individuos sospechosos de prácticas criptojudías era inculpar a otras personas que pudieran estar en esa misma situación y también, sin recato, algunos de los inquisidores, encontraban la posibilidad de incautar propiedades que pudieran pasar a propiedad del Santo Oficio. Los voluminosos expedientes son ahora una fuente rica de información respecto a prácticas comerciales, costumbres, preferencias del consumo, contacto con múltiples sectores de la política, el comercio, la jerarquía católica en Filipinas y en México, entre otros elementos. Desde el análisis de redes, es posible extraer tales vinculaciones y determinar contactos que se extendían por la vasta región asiática, varias ciudades de América y, por supuesto, España y Portugal.

La información disponible en la sección Inquisición del Archivo General de la Nación (AGN), en México, enriquece el estudio del contexto sociohistórico para interpretar la extensión de las relaciones comerciales. Diversos archivos en México, España, Portugal y Filipinas permiten rastrear varias redes de comerciantes de origen portugués, identificados como cristianos nuevos, es decir, como judíos conversos, en el siglo XVI. El cruce de información en el estudio de la red posibilita el análisis de la parte oscura de los perseguidos y de la parte clara de los comerciantes con éxito.

Por ejemplo, una fuente inusual que complementa las denuncias y los procesos inquisitoriales es el Archivo de Notarías de la Ciudad de México, que apenas desde el presente siglo hizo posible la consulta de su documentación, gracias a un esfuerzo de reordenamiento y digitalización dirigido por historiadores de la Universidad Nacional Autónoma de México (UNAM).

El marco conceptual de la investigación inició con la interpretación de Philip Curtin (1994) acerca del comercio intercultural, mencionado. Los conceptos centrales de esta interpretación son: primero, el estudio de los asentamientos de intercambios ambulantes en comunidades extranjeras. Segundo, las habilidades de los comerciantes para interactuar y negociar con sus contrapartes, utilizando idiomas y aceptando rituales que facilitaban el intercambio. La descripción de estas habilidades se toma de Abner Cohen (Cohen 1969). Tercera, el concepto de puerto de comercio, desarrollado en gran medida por Karl Polanyi y algunos de sus seguidores, es central para la investigación. Este modelo reconoce la existencia de otras formas de comercio, especialmente, en la era capitalista premoderna, las cuales no estaban gobernadas esencialmente por la oferta 
y la demanda o las fuerzas del mercado. Esta formas pueden ser la redistribución, la reciprocidad y el intercambio (Polanyi 1963).

\section{Historia digital, historia global y microhistoria}

Diversos estudios sobre el comercio trans-Pacífico se han basado en la series de cuentas anuales de las aduanas reales que eran enviadas a la metrópoli y que fueron cuidadosamente acumuladas en el Archivo General de Indias. Como mencioné, Pierre Chaunu extrajo de esta fuente un análisis valioso de interpretación (Chaunu 1974). Sin embargo, el análisis de esta información enfrenta grandes dificultades tanto en la secuencia de datos como en la clasificación de mercancías. Algunos aspectos que, por definición, no aparecen en las series de datos, por ejemplo, son el costo de la corrupción, el contrabando y el comercio local y regional no registrado (Wills 2011). Este es el tipo de big data, es decir, gran volumen de información, que ofrece oportunidades de análisis, pero también incertidumbre. Los matemáticos y epidemiólogos denominan esta situación como inconmensurable, por lo que su tratamiento requiere establecer estrategias para ser interpretada.

Este es el tipo de retos que enfrenta casi toda la investigación de la historia global, además de la variedad de idiomas y problemas de clasificación en cada uno de los archivos. Gracias a la digitalización de mucha documentación es posible acceder a documentos identificados durante las jornadas de investigación, y precisar contenidos o verificar relaciones que pasaron desapercibidas. La digitalización de los archivos no sustituye la inspección directa de las fuentes y las conexiones de la documentación, que no aparecen en línea. El trabajo solitario del historiador se ha visto enriquecido por las comunidades virtuales que permiten un diálogo de múltiples voces en diversas latitudes. Por insólito que parezca, las redes sociales, como Twitter, permiten conocer detalles de otras investigaciones y anuncian hallazgos muy especializados, útiles para la comunidad de historiadores.

Una herramienta de gran beneficio en este campo de conocimiento es el análisis de redes y la posibilidad que abre para diseñar una visualización de estas (Kerschbaumer, Keyserling Stark y Düring 2020). Para revisar la consistencia de las relaciones que estudié en archivos, fue necesario definir primero cada tipo de relación (ontología) entre los comerciantes, catalogados como vínculos comerciales, de parentesco, religiosos o políticos. Por ejemplo, las relaciones de un individuo como socio comercial, cliente o pariente. Cada persona identificada como comerciante es conocida como nodo de la red. De esta forma, la red aparece con claridad por la extensión que abarca desde Asia a América y Europa, y por la intensidad de contactos en un plazo relativamente breve de una década, la última del siglo XVI.

\section{Conclusión}

Este artículo se sitúa en la etapa inicial del Galeón de Manila, visto desde el ángulo de una de las redes globales de comercio. Este contribuyó a la creación de un sistema comercial en el último cuarto del siglo XVI. Con este enfoque, basado en documentación de múltiples archivos, fue posible observar el detalle (los árboles), lo cual enriquece el análisis general (el bosque), y contribuye a ilustrar un proceso que ha ganado la atención de los historiadores: el de las redes de comercio intercultural de larga distancias.

El problema de la complejidad es que mezcla fenómenos de largo alcance como son los imperios, las religiones, las poblaciones y sus culturas tan diversas, de las que los europeos tenían poco o nulo conocimiento en esa época. Un aspecto central esbozado en este texto es que la cultura es la fuerza que pone en contacto, confronta y resuelve conflictos en las diversas partes de un sistema global. Ese fermento cultural fructifica notablemente entre los miembros de las redes de mercaderes, quienes desarrollan sus actividades en espacios alejados de su lugar de origen. En estos lugares se adaptan y establecen múltiples diálogos con comerciantes y autoridades de otras latitudes. Los europeos, encabezados por las naciones ibéricas pusieron en marcha 
estrategias de dominación cultural, sobre todo el barroco como expresión política. Asimismo, las redes y los individuos que emprendieron esas estrategias utilizaron técnicas culturales que les permitieron avanzar en el comercio intercultural: desde la cartografía, la navegación, la contabilidad, la traducción, la práctica notarial, entre otras.

El reto es integrar los aspectos comerciales, políticos y religiosos para comprender, de manera coherente, el contexto histórico del intercambio del Galeón de Manila, sistema de comercio de mayor duración en la historia. La amplia literatura sobre el tema tiende de manera natural a la generalización, y son comunes los enfoques teleológicos o que hacen pensar en una situación inmutable y ahistórica. Las aportaciones más valiosas remiten a los cambios que se dieron en el sistema de comercio y que permitieron su reforma. Estas adecuaciones le dieron continuidad al sistema, a través de los siglos, para responder a la competencia holandesa e inglesa en el terreno comercial asiático.

\section{Referencias}

Archivo General de la Nación (AGN), México, Inquisición, vol. 162, Proceso en contra de Diego Hernández Victoria. AGN, México, Inquisición, Vol. 251, exp.1, año 1599. Testamento de Diego Hernández Vitoria.

AGN, México, Inquisición, vol, 159, exp. 1. Proceso en contra de Antonio Diaz de Cáceres, Natural de Santa Combadan en Portugal, por judaizante. Años 1596-1601.

Archivo General de Indias (AGI), Patronato, "Información de los méritos y servicios del capitán Bartolomé Báez Landero contraídos en Filipinas, China e isla de Macán, y otras de Asia durante 28 años", Manila. 19 de abril de 1586.

Albert, Salvador Bernabeu (ed.) (2013) La Nao de China, 1565-1815. Navegación, Comercio e Intercambios Culturales. Sevilla: Universidad de Sevilla.

Atwell, William S. (2008). "Ming China and the Emerging World Economy, c. 1470-1610." In The Cambridge History of China, Volume 8, The Ming Dynasty, 1368-1644, Part 2. Cambridge: Cambridge University Press.

Bakewell, Peter (1984). "Mining in Colonial Spanish America." In The Cambridge History of Latin America, Leslie Bethell (ed.) Cambridge: Cambridge University Press: 105-152.

Barreto, Luís Filipe (2016). Macau: Poder e Saber. Séculos XVI e XVII. Lisboa: Editorial Presença.

Bayly, C.A. (2004) The Birth of the Modern World, 1780-1914: Global Connections and Comparisons. The Blackwell History of the World. Malden, MA: Blackwell Pub: $42-44$

Bin, Yang (2019) Cowrie Shells and Cowrie Money: A Global History. London: New York: Routledge Approaches to History.

Bonialian, Mariano. (2012) "Las Aguas Olvidadas Del Mar Del Sur, Comerciantes Novohispanos y Sus Reexportaciones de Mercaderías Extranjeras Hacia El Perú (1680-1740).” Historia Mexicana 61, no. 3 (243): 995-1047. https://doi.org/10.2307/41303939.

Mariano Bonialian (2015) “Asiáticos en Lima a principios del siglo XVII.” Bulletin de L’Institut Français détudes Andines, 44(2): 205-236.

Borah, Woodrow. (1975) Comercio y Navegación Entre México y Perú En El Siglo XVI, México: IMCE.

Böttche, Nikolaus, Bernd Hausberger y Antonio Ibarra (2011). Redes y Negocios Globales en el Mundo Ibérico Siglos XVI-XVIII. Madrid Frankfurt: Iberoamericana/Vervuert/El Colegio de México.

Boyajian, James C. (1983). Portuguese Bankers at the Court of Spain, 1626-1650. New Brunswick, NJ: Rutgers University Press.

Boyajian, James C. (1993). Portuguese Trade in Asia Under the Habsburgs, 1580-1640. Baltimore, MD: Johns Hopkins University Press.

Boxer, Charles R.(1948). Fidalgos in the Far East 1550-1770. Fact and Fancy in the History of Macao. The Hague: Martinus Nijhoff. 
Cardim, Pedro, Tamar Herzog, José Javier Ruíz Ibañez, Gaetano Sabatini. (2014) Polycentric Monarchies. How Did Early Modern Spain and Portugal Achieve and Maintain a Global Hegemony? Sussex: Sussex Academic Press.

Dennis Carr, Gauvin Bailey, Timothy Brook, Mitchell Codding, Karina Corrigan, and Donna Pierce. (2015) Made in the Americas: The New World Discovers Asia. Boston, New York: Museum of Fine Arts Publications.

Chaunu, Pierre (1974) Las Filipinas y El Pacifico de Los Ibéricos. Siglos XVI-XVIII. Estadisticas y Atlas. México: Instituto Mexicano de Comercio Exterior. Mexico: IMCE.

Cohen, Abner (1971) "Cultural strategies in the organization of trading diasporas", publicado en The Development of Indigenous Trade and Markets in West Africa: Studies Presented and Discussed at the Tenth International African Seminar at Fourah Bay College, Freetown, December 1969, C. Meillassoux éd., Londres, International African Institute: Oxford University Press: 266-278.

Curtin, Philip (1948) Cross-Cultural Trade in World History, Cambridge. New York: Cambridge University Press.

Curiel, Gustavo (2016). "De Cajones, Fardos y Fardillos. Reflexiones en torno a las cargazones de mercaderías que arribaron desde el Oriente a la Nueva España." en A 500 Años del Hallazgo del Pacífico. La Presencia Novohispana en el Mar Del Sur. Carmen Yuste López y Guadalupe Pinzón Ríos (Coordinadoras). Mexico: UNAM: 191-216.

Echeverría, Bolivar (2014), La modernidad de lo barroco. México: Ediciones Era.

Echeverría, Bolivar (2014), La modernidad de lo barroco. México: Ediciones Era.

Gasch-Thomas, José (2014). "Globalisation, Market Formation and Commodtisation in the Spanish Empire. Consumer Demand for Asian Goods in Mexico City and Seville, c. 1571-1630." Revista de Historia Económica 32, no. 02: 189-221.

Garcia Fuentes, Lutgardo (1997) Los peruleros y el comercio de Sevilla con las Indias, 1580-1630. Sevilla: Universidad de Sevilla.

Gasch-Thomas, José (2014). "Globalisation, Market Formation and Commodtisation in the Spanish Empire. Consumer Demand for Asian Goods in Mexico City and Seville, c. 1571-1630." Revista de Historia Económica 32, no. 02: 189-221.

Giráldez, Arturo(2005) “La Economía Global y El Quijote.” Revista Historia Económica XXIII.

Giraldez, Arturo (2015).The Age of Trade. The Manila Galleons and the Dawn of the GlobalEconomy. Lanham, Boulder, New York, London: Rowman \& Littlefield: 149.

Gruzinski, Serge (2014). The Eagle and the Dragon: Globalization and European Dreams of Conquest in China and America in the Sixteenth Century. 1 edition. Malden, MA: Polity.

Hausberger, Bernd y Antonio Ibarra. (2014). Oro y Plata en los Inicios de la Economía Global: De las Minas a la Moneda. México: El Colegio de México.

Herrero Sánchez, Manuel y Klemens Kaps (2017). "Connectors, networks and commercial systems: approaches to the study of early modern maritime commercial history", en Herrero Sánchez y Klemens Kaps (Eds). Merchants and Trade Networks.

Herrero Sánchez, Manuel y Klemens Kaps. (2017). Merchants and Trade Networks in the Atlantic and the Mediterranean, 1550-1800: Connectors of Commercial Maritime Systems. I edition. London; New York: Routledge.

Herzog, Tamar (2011). Defining Nations: Immigrants and Citizens in Early Modern Spain and Spanish America. New Haven: Yale University Press.

Hidalgo Nuchera (ed) (1995). Los primeros de Filipinas. Crónicas de la conquista del archipiélago. Madrid, Miraguano Ediciones: 36.

Iaccarino, Ubaldo (2011) “The 'Galleon System' and Chinese Trade in Manila at the Turn of the 16th Century." Ming Wing Yanjiu CVI: 95-128.

Irving, D.R.M. (2010.) Colonial Counterpoint: Music in Early Modern Manila. 1 edition. Oxford; New York: Oxford University Press, 2010.

Iwasaki, Fernando (2011). “Primeros Contactos Entre Perú y Japón En El Siglo XVI.” Embajada Del Perú en China 
Kai, Zhang (1977) Diego Pantoja y China (1597-1618). Un estudio sobre la politica de adaptación de la Compañia de Jesús. Beijing: Agencia Española de Cooperación Internacional.

Kerschbaumer, Florian, Linda von Keyserlingk-Rehbein, Martin stark y Martin Düring. (Eds.) (2020). The Power of Networks. Prospect of Historical Network Research. London and New York: Routledge, Taylor \& Francis Group.

Lieberman, Victor (2003). Strange Parallels: Volume 1, Integration on the Mainland: Southeast Asia in Global Context, c.800-1830. New York: Cambridge University Press

Machuca, Paulina (2014). "The Arrival of American Plants in the Philippines: Ecological Colonialism in the Sixteenthto-Eighteentf Centuries." Anais de História de Além-Mar XV: 251-60.

Miyata, Etsuko (2017). Portuguese Intervention in the Manila Galleon Trade: The Structure and Networks of Trade Between Asia and America in the 16th and 17th Centuries as Revealed by Chinese Ceramics and Spanish Archives. Oxford: Archaeopress Archaeology.

Molho, Anthony, Diogo Ramada Curto y Christine Piot. (2003). "Les Réseaux Marchands à l'époque Moderne." Annales. Histoire, Sciences Sociales 58, no. 3: 569-79.

Mukherjee, Rila (Ed.) (2011). Networks in the First Global Age: 1400-1800. 1 edition. New Delhi: Primus Books. Rlla Mukherjee (Ed.). Rila Mukherjee (Ed.) (2013) Oceans Connect: Reflections on

Rlla Mukherjee (Ed.). Rila Mukherjee (Ed.) (2013) Oceans Connect: Reflections on Water Worlds across Time and Space. 1 edition. Delhi: Primus Books.

O 'Gorman, Edmundo (1995). La Invención de América. Investigación Acerca de la Estructura Histórica Del Nuevo Mundo y del Sentido de su Devenir. México: Fondo de Cultura Economica

O 'Flynn, Dennys y Arturo Giráldez (1995), “Born with a "Silver Spoon”: The Origin of the World Trade in 1571". Journal of World History, 6, no. 2, University of Hawai 'i Press.

O'Flynn y Giráldez (2002). "Cycles of Silver, Global Economic Unity through the Mid Eighteenth Century", The Journal of World History, 13, 2, University of Hawai'i Press: 391-427.”

O. Flynn, Dennis y Arturo Giráldez (1988). "The Pacific Rim Deserves a Future." In Studies in the

Oropeza Keresey, Deborah (2011). “La Esclavitud Asiática En El Virreinato de La Nueva España, 1565-1673.” Historia Mexicana, Colmex, 61, No.1: 5-57.

Owens, J.B. (2011). "What Kind of System Is It? The DynCoopNet Project as a Tribute to Andre Gunder Frank (1929-2005)." In Networks in the First Global Age 1400-1800, Edited by Rila Mukherjee, 3-10. New Delhi: Primus Books.

Penalva, Elsa (2008). "Merchant Elites of Macao in 1642." Bulletin of Portuguese -Japanese Studies

Polanyi, Karl (2001, original de 1944) The Great Transformation, The Political and Economic Origins of Our Times Boston: Beacon Press.

Polanyi, Karl (1963). "Ports of Trade in Early Societies." The Journal of Economic History 23, no. 1: 30-45.

Polónia, Amélia, Amândio Barros, and Miguel Nogueira. (2011) "Now and Then, Here and There ... on Business": Mapping Social/Trade Networks on First Global Age.” In Mapping Different Geographies, edited by Karel Kriz, William Cartwright, and Lorenz Hurni, 105-28. Lecture Notes in Geoinformation and Cartography. Springer Berlin Heidelberg.

Pomeranz, Kenneth y Steven Topik. (2013). The World that Trade Created: Society, Culture, and the World Economy 1400 to the Present. New York: Routledge.

Reed, Robert R. (1978). Colonial Manila. The Context of Hispanic Urbanism and Process of Morphogenesis. Berkeley, CA: University of California Press.

Jeremy Tambling. (2009). Walking Macao, Reading the Baroque. Hong Kong: Hong Kong University Press.

Ribeiro, Ana Sofia (2015). Early Modern Trading Networks in Europe: Cooperation and the Case of Simon Ruiz. 1 edition. Abingdon, Oxon; New York, NY: Routledge.

Seijas, Tatiana (2008). “The Portuguese Slave Trade to Spanish Manila: 1580-1640.” Itinerario 32, no. 01: 19-38

Sousa, Lucio (2010). The Early European Presence in China Japan the Philippines and Southeast Asia. Macau: Macau Foundation. 
Spate, Oscar (2004). The Spanish Lake. Canberra: The Australian National University. http://press.anu.edu.au/title s/spanish_lake_citation/.

Studnicki-Gizbert, Daviken (2007). A Nation upon the Ocean Sea: Portugal 's Atlantic Diaspora and the Crisis of the Spanish Empire, 1492-1640. Oxford; New York: Oxford University Press.

Suárez, Margarita (2015). "Sedas, Rasos y Damscos: Lima y el cierre del comercio triangular con México y Manila en la primera mitad del siglo XVII." America Latina en la Historia Economica 22: 101-34.

Suárez, Juan Luis, Fernando Sancho-Caparrini, Shiddarta Vasquez. (2012) "The Potosí Principle: Religious Prosociality Fosters Self-Organization of Larger Communities under Extreme Natural and Economic Conditions." Literary and Linguistic Computing 27, no. 1: 25-38.

Subrahmanyam, Sanjay (2012). The Portuguese Empire in Asia, 1500-1700: A Political and Economic History. West Sussex, UK: John Wiley \& Sons, 2012.

Trivellato, Francesca (2011) "Is There a Future for Italian Microhistory in the Age of Global History?" California Italian Studies 2, no. 1.

Trivellato, Francesca, Leor Halevi y Catia Antunes (Eds.) (2014). Religion and Trade: Cross-Cultural Exchanges in World History, 1000-1900. Oxford University Press.

Uchmany, Eva Alexandra (1992). La vida entre el judaísmo y el cristianismo en la Nueva España 1580-1606. México: Fondo de Cultura Económica / Archivo General de la Nación.

Uchmany, Eva Alexandra (1998). Las Relaciones Mercantiles entre México y el subcontinente Indio durante la Época Colonial, en México-India. Similitudes y encuentros a través de la historia. México: Fondo de Cultura Económica:70-103.

Valle Pavón, Guillermina del (2005). “Los Mercaderes de México y la transgresión de los límites al comercio Pacífico en Nueva España, 1550-1620", Revista de Historia Económica, vol. XXIII: 213- 240.

Von Glahn, Richard (2016) The Economic History of China. Reprint edition. Cambridge: Cambridge University Press.

Villamar, Cuauhtémoc (2015). "Juan de Palafox y China." Estudios de Historia Novohispana 52: 44- 60.

Villamar, Cuauhtémoc (2016) "El Galeón en la región asiática", en Tornaviaje, La Nao de China y El Barroco en México, 1565-1815, Museo Internacional del Barroco, Puebla México: 44-51.

Weisbach, Werner(1948). El Barroco, arte de la Contrarreforma. Madrid: Espasa-Calpe.

Wills, John W. Jr. (2011). China and Maritime Europe, 1500-1800, Trade Settlement, Diplomacy, and Missions. Cambridge: Cambridge University Press: 53-54.

Yuste, Carmen (2007) Emporios transpacíficos: comerciantes mexicanos en Manila, 1710-1815. México: UNAM.

Yuste, Carmen (ed.) (2019) Nueva España, Puerta Americana al Pacífico Asiático. Siglo XVI-XVIII. Mexico: UNAM Instituto de Investigaciones Históricas. http://www.historicas.unam.mx/publicaciones/publicadigital/libros/7 05/nueva_espana.html

\section{Notas}

* Artículo de Investigación.

1 Existe una amplia literatura acerca del Galeón de Manila, pero el libro de William Lyte Schurz. (1939) The Manila Galleon, New York: Dutton \& Company, continúa siendo el más completo en la materia. Los lectores también pueden consultar el libro en línea de Oscar H.K. Spate. (2004 The Spanish Lake. Canberra: The Australian National University. http://press.anu.edu.au/titles/spanish_lake_citation/. Un texto contemporáneo en español que abarca el largo plazo del comercio es Carmen Yuste. (2007) Emporios transpacificos: comerciantes mexicanos en Manila, 1710-1815. México: UNAM. Salvador Bernabeu Albert (ed.) (2013) La Nao de China, 1565-1815. Navegación, Comercio e Intercambios Culturales. Sevilla: Universidad de Sevilla. Carmen Yuste (ed.) (2019) Nueva España, Puerta Americana al Pacifico Asiático. Siglo XVI-XVIII. Mexico: UNAM Instituto de Investigaciones Históricas. http://www.historicas.unam.mx/p ublicaciones/publicadigital/libros/705/nueva_espana.html. 
2 De hecho, el primer viaje desde Filipinas a Amèrica fue el del galeòn San Pedro, que zarpó desde Cebú el primero de junio de 1565 y llegó al puerto de La Navidad el primero de octubre de ese año. El mérito de ese trayecto fue descubrir el Tornaviaje. Patricio Hidalgo Nuchera (ed) (1995) Los primeros de Filipinas. Crónicas de la conquista del archipiélago. Madrid, Miraguano Ediciones: 36

3 Coincido en parte con el concepto de Ubaldo Iaccarino al denominar al Galeón de Manila como un sistema. En este caso, hago una descripción especifica de la estructura y de las reglas que determinaban ese sistema. Ubaldo Iaccarino. (2011) "The 'Galleon System ' and Chinese Trade in Manila at the Turn of the 16th Century." Ming Wing Yanjiu CVI: 95-128.

4 Los castellanos y mexicanos que ocuparon las Filipinas no encontraron suficientes especias, pero sí una enorme variedad de productos de toda Asia. Cuauhtémoc Villamar (2016) "El Galeón en la región asiática", en Tornaviaje, La Nao de China y El Barroco en México, 1565-1815, Museo Internacional del Barroco, Puebla México: 44-51.

5 El termino intercultural como traducción de cross-cultural que es el término empleado por Philip Curtin. (1948) CrossCultural Trade in World History, Cambridge. New York: Cambridge University Press.

6 La idealización contemporánea del mercado induce a pensar que la sociedad es un únicamente un anexo del mercado. En lugar de pensar que la economía está integrada en las relaciones sociales, se suele pensar que el sistema económico precede a las relaciones sociales.

7 Los comerciantes viajaban para obtener productos diferentes o escasos. Este autor coloca el énfasis en las diásporas, grupos o colonias de mercaderes que se desplazaban por largas temporadas en aras de su comercio.

8 En la actualidad, la conmemoración de la caída del imperio mexica en 1521 ha abierto a la discusión la naturaleza misma de la(s) conquista(s) de América. Resaltan por su gran valor para la reflexión dos trabajos: Edmundo O 'Gorman.(1995). La Invención de América. Investigación Acerca de la Estructura Histórica Del Nuevo Mundo y del Sentido de su Devenir. México: Fondo de Cultura Economica, y Bolivar Echeverría. (2014). La modernidad de lo barroco. México: Ediciones Era.

\section{Licencia Creative Commons CC BY 4.0}

Cómo citar este artículo: Villamar, C. (2020). Redes mercantiles e intercambio cultural en la ruta del Galeón de Manila, 1565-1600. Universitas Humanística, 89. https://doi.org/10.11144/Javeriana.uh89.rmic 